\title{
THE ROLE OF PREFERENCE IN THE CONTINUITY OF TECHNOLOGICAL USE
}

\author{
Edgardo R. Bravo, Universidad del Pacifico,er.bravooo@up.edu.pe \\ Christian Fernando Libaque-Saenz, Universidad del Pacifico, cf.libaques@up.edu.pe
}

\begin{abstract}
Previous models assume the presence of a single technology to predict its continuance. However, this assumption is challenged since individuals are often exposed to multiple technologies on which they must decide whether or not to continue using a given one. On this basis, this article develops a conceptual framework integrating models of continuity of use and preference. The incorporation of technological alternatives can lead to a greater understanding of the phenomenon of continuance and to improve the explanatory power of the models. The study proposes that management should consider not only endogamic causes (referred to incumbent technology such as usefulness or satisfaction) but also comparative factors (related to alternatives like the preference) to improve continuance use of their technologies.
\end{abstract}

Keywords: Continuity of use, preference, attitude, intention, satisfaction

\section{INTRODUCTION}

Organizations increasingly invest in technology. Statistics show that the level of investment is around $\$ 3.8$ trillion per year (Drew et al., 2014). However, empirical evidence suggests that individuals do not use technologies in all of their full potential (Viswanath Venkatesh, Brown, Maruping, \& Bala, 2008). Research also shows that it is more costly to recruit new users than to maintain the existing ones (Bhattacherjee, 2001). In this sense, the study of the continuity of use is especially relevant to the research in marketing and information systems (IS) (Shaikh \& Karjaluoto, 2015).

The IS literature has focused on explaining the so-called "continuity of use" behavior by distinguishing it from "adoption" behavior (Jasperson, Carter, \& Zmud, 2005). Several models in the literature have explained this latter behavior (Hong, Thong, \& Tam, 2006; V. Venkatesh, Thong, \& Xu, 2012). However, the Bhattacherjee (2001)'s work -Expectation Confirmation Model (ECM)- has become the most predominant in the field (Hossain \& Quaddus, 2012). In this model, the intention to continue using technology is explained by the satisfaction with the previous experience of use and the perceived usefulness. In turn, these constructs are explained by the confirmation of expectations.

One assumption of this model is that it predicts continuity of use considering the presence of a single technology. In this way, the constructs of the model are related to the usefulness, satisfaction, ease of use and confirmation of expectations of that unique technology. Although several studies have applied and extended this model to several contexts, these works have not challenged this assumption (e.g. Hong et al., 2006; Thong, Hong, \& Tam, 2006). However, it is common for individuals to evaluate the continuity of use of a technology under the presence of one or more alternative technologies. For example, when an individual uses a search engine has probably available another or other search engines, or when an individual uses a data warehouse in the cloud, they may also have other alternatives. In this context, studies that do not contemplate the presence of other options may lead to incomplete conclusions (Lin, Chan, \& Wei, 2011, p. 21; Muthitcharoen, Palvia, \& Grover, 2011, p. 206) or with less explanatory power (Lin, Chan, \& Wei, 2006, p. 1332). Hence, the question that arises is how to incorporate the presence of alternatives in the model of continuity of use.

The repurchase intention literature considers the presence of alternatives using the concept of preference (Hellier, Geursen, Carr, \& Rickard, 2003). The preference construct suggests an active state of preferring one object to another because the first one is perceived better (Kivetz, Netzer, \& Schrift, 2008). Preferences also involve ordering 
different options regarding expected levels of happiness, gratification, usefulness, etc. (Samson, 2015). When consumers begin to consume a particular category of products, they generally show very little evidence of a preference for any. As they gain more information on a product and have a higher buying experience, the likelihood of choosing a particular product increases (Devaraj, Fan, \& Kohli, 2002, p. 318). This literature suggests that preference has an impact on the repurchase intention beyond the satisfaction as proposed by the ECM.

In summary, the literature seems to have supposed the absence of alternative technologies to predict the intention of continuity of use. However, it is notorious that this assumption is challenged, in multiple contexts, by the daily exposure of users to technological alternatives. Our research proposes a model that introduces factors related to the presence of alternative technologies, based on the literature on preference.

At the theoretical level, this research would provide a conceptual framework that improves the understanding of the continuance when the individual has alternatives. In this way, the notion of the continuity of use would be extended considering not only base technology constructs but also constructs relative to technological options available to the user. At the practical level, it would help management to develop strategies that not only affect an endogamic factor such as satisfaction but an exogenous variable such as preference.

\section{BACKGROUND}

\section{Theory of Technological Continuity (TTC)}

Continuance refers to the long-term or sustained use of technology (Bhattacherjee \& Lin, 2014, p. 1). The ECM Figure 1a- proposes that the intention of continuity of use has three antecedents: the satisfaction of the user with the technology; the confirmation of the user's previous expectations about the performance of the technology; and the perceived usefulness of the technology (that represent post-acceptance expectations).

Although the ECM is one of the most used models to explain the intention of continuity of use in the technological context, it ignores a construct that is widely recognized as essential for predicting behavioral intention: attitude (Liao, Palvia, \& Chen, 2009; Muthitcharoen et al., 2011).

In order to improve the models of continuity of use of technologies, Liao et al. (2009) makes an evaluation of three of the most used ones: the ECM (Bhattacherjee, 2001), the TAM (Davis, Bagozzi, \& Warshaw, 1989), and the Cognitive Model of Satisfactory Decisions -COG-(Richard L. Oliver, 1980). They conclude that each model has different assumptions about its constructs and therefore, they have distinct degrees of explanatory power of intention. In this sense, when synthesizing the most important constructs in the three previous models, Liao et al. (2009) propose the Theory of Technological Continuity (TTC) - Figure 1b -, which includes the attitude and satisfaction based on the higher explanatory level they provide.

The theoretical interest in the TTC is twofold. On the one hand, it shows the role of the attitude in the formation of the intention, and on the other side, the presence of the attitude will serve as a nexus with the preference model in the decision-making process which is reviewed below.

\section{The preference in the decision making}

Although the revised models of continuity are widely used, they do not explicitly consider the availability of alternative technologies that users can access and on which they may have some degree of preference.

A similar problem faced the models of technological adoption (e.g., TAM), where evaluation is performed as an indirect and implicit comparison of new technology with a current one (Davis et al., 1989). However, these models do not explicitly take into account the role of preference and how it might affect the decision to adopt a technology (Jaafar, Darmawan, \& Mohamed Ariffin, 2014).

A model that confronts this problem is the one proposed by Muthitcharoen et al. (2011) and called Technology Preference Model (TPM) -Figure 1c-. The TPM explains the selection of an alternative based on user preference in the context of using sales channels (online or physical). In this way, the preference variable implies the explicit 


\section{Issues in Information Systems \\ Volume 19, Issue 3, pp. 42-52, 2018}

comparison between the alternatives that the user does, which impacts on the decision processes on the use of a specific channel (a technology, in this case).

This model is based on the TAM and the literature of preference. The TPM supports the levels of comparison between alternatives that an individual might have. The TAM provides an implicit comparison level, for which it uses variables that correspond to the evaluation of a new option proposed to the user (perceived usefulness and ease of use). On the other hand, the literature of preference provides an explicit comparison, on which users directly compare between the current technology in use and the new one. Muthitcharoen et al. (2011) consider variables that account for the user's preference: attitude based on preference and attributes based on the preference. This approach proposes that new and current alternatives are compared in detail (a level of characteristics) before users develop a general preference, which ultimately influences attitude toward behavior (Einhorn, 1971; Tversky, 1969).

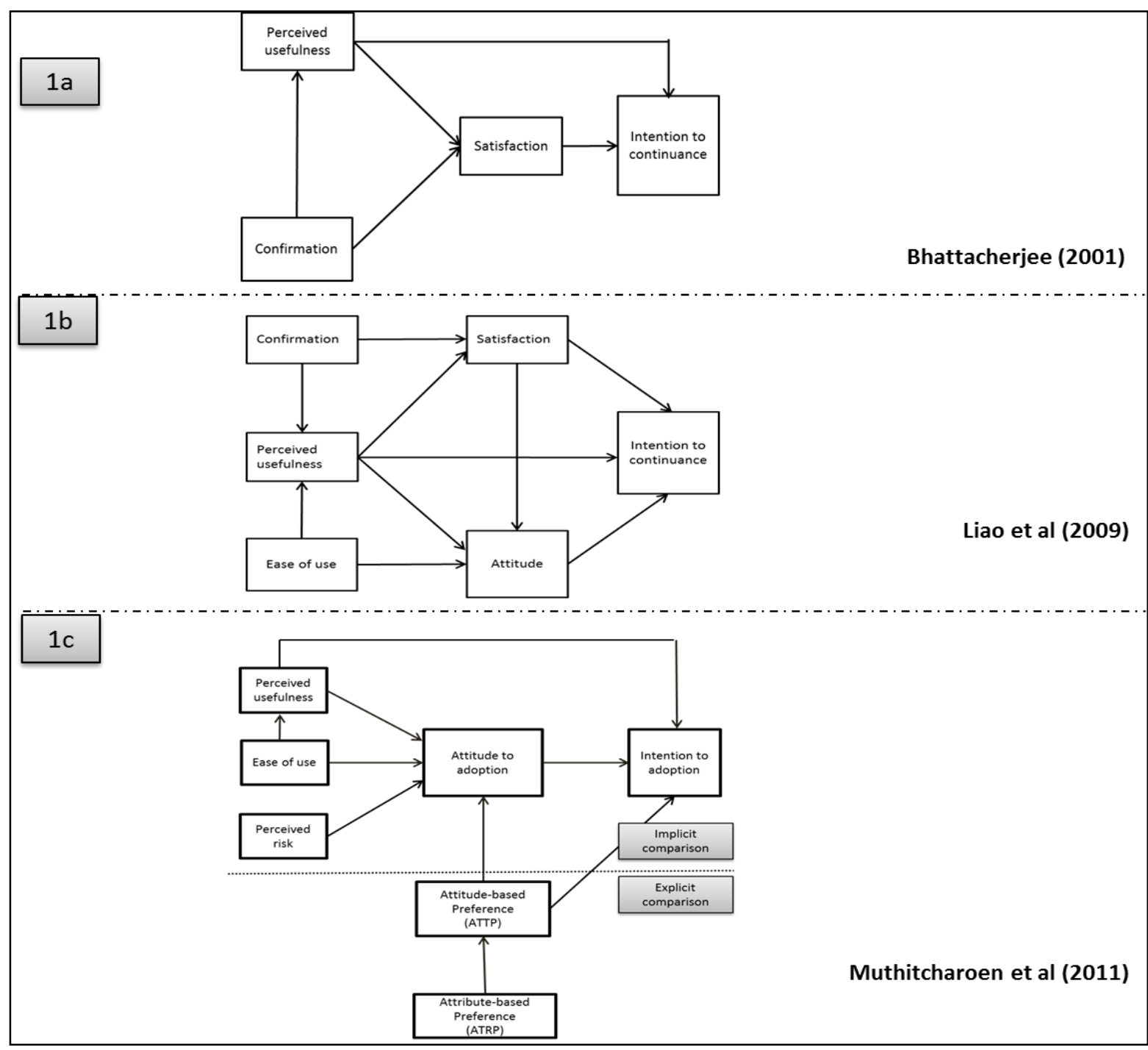

Figure 1. Continuance Model and Preferences

Thus, the level of explicit comparison is an outstanding theoretical contribution, since it models the preference as a general attitude of the user towards an alternative. Therefore, this results in a comparative evaluation. Likewise, the 


\section{Issues in Information Systems}

Volume 19, Issue 3, pp. 42-52, 2018

comparison is established among the attributes of the options, especially in cases where the technology has not been used previously, and it proposes that the characteristics are also based on preference.

Although the TPM has been developed in the field of technological adoption, it is considered relevant to integrate it into the area of continuity. According to Dabholkar (1994) the comparison of a level of attitudes is more suited when the individual is familiar with the technologies and has been able to form a stable and lasting disposition of the technologies. The latter is appropriately configured in the phenomenon of continuity of use.

\section{RESEARCH MODEL}

The research model - Figure 2 - is presented in two sections. First, we develop (continuous lines) the hypotheses derived from the TTC model, and (in broken lines) the hypotheses suggested by TPM and marketing preference literature.

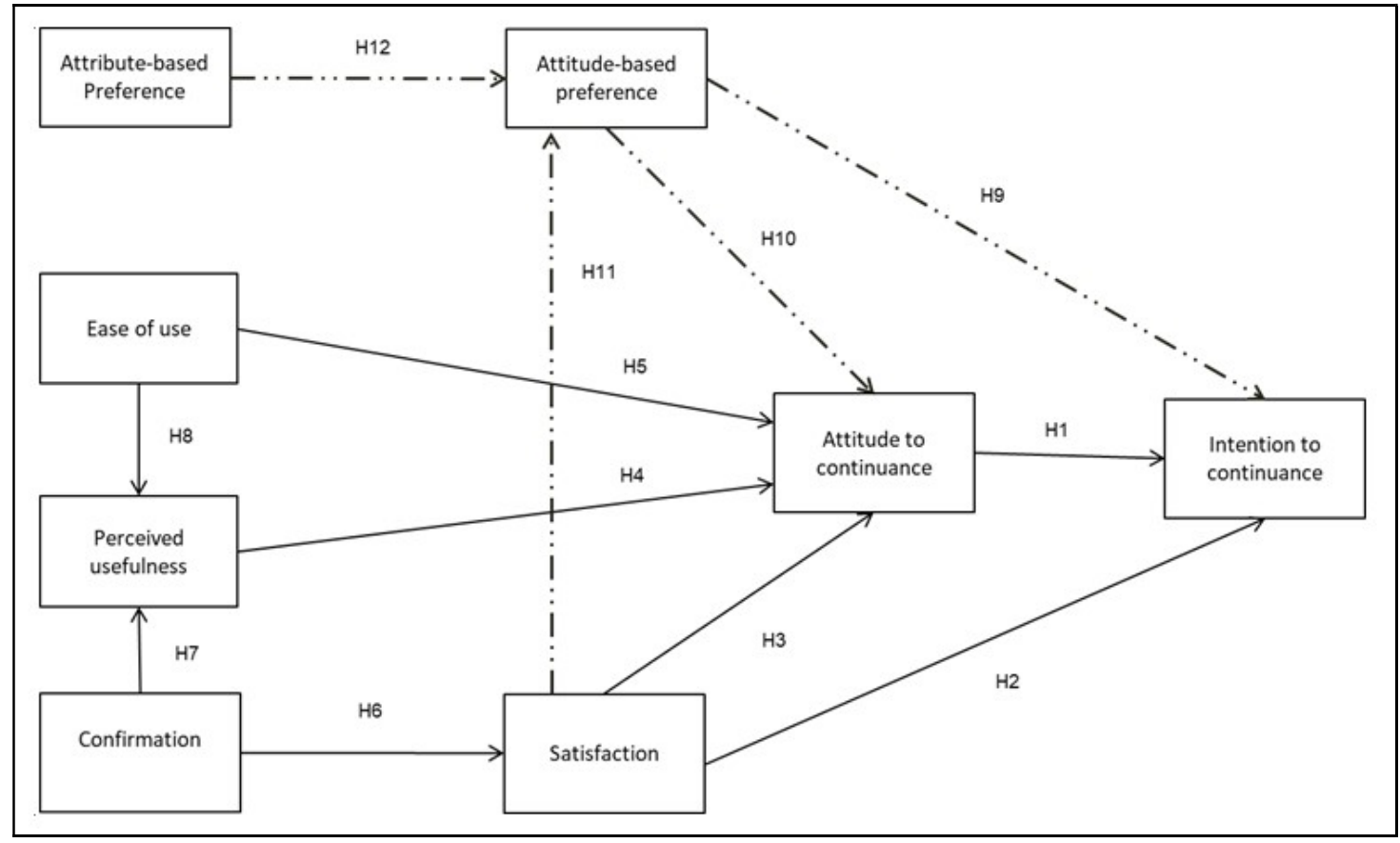

Figure 2. Research Model

\section{Continuity of use}

An intention indicates the subjective probability that an individual performs a given behavior (Fishbein \& Ajzen, 2011 , p. 39). Therefore, the intent to continue use may be understood as the likelihood that an individual will continuously use a particular technology.

Attitude refers to the positive or negative evaluation by an individual concerning a particular behavior (Ajzen, 1991, p. 188). Therefore, the attitude is related to the affective assessment related to the continuity of use (Liao et al., 2009).

TTC considers attitude as a relevant concept in the prediction of behavioral intention. Conceptually, it is expected that the intentions of performing a particular behavior will be stronger as long as the individual has favorable attitudes to such behavior (Fishbein \& Ajzen, 2011, p. 181).

Based on the above, it is proposed: 


\section{Issues in Information Systems}

Volume 19, Issue 3, pp. 42-52, 2018

H1: Attitude to continuance influences intention to continuance positively.

Satisfaction refers to the affection captured as a positive (satisfied), indifferent, or negative (unsatisfied) feeling after the use of a technology (Bhattacherjee, 2001). It differs from the attitude to the extent that satisfaction is an affective evaluation post-use and, therefore, it is specific to a context of use, and it is transient in time, while attitude is a more general and enduring evaluation over time (Bolton \& Drew, 1991; Liao et al., 2009).

The TTC proposes that the intention of the users to continue using technology is mainly determined by the satisfaction. Conceptually, users perform a post-use evaluation of technology. To the extent that use has generated positive (or adverse) affects, the individual will feel satisfied (or dissatisfied), and therefore, the individual would have a higher intention to continue (or discontinue) the use of a technology (Bhattacherjee, 2001).

Based on the above, the following hypothesis is proposed:

H2: Satisfaction is positively related to intention to continuance.

TTC also proposes a link between satisfaction and attitude towards continuity of use. Although both constructs represent affections about the use of technologies (Bhattacherjee \& Premkumar, 2004). However, conceptually, since satisfaction is a more specific and transitory affection that occurs after having used technology, this would affect the formation of a more general and persistent evaluation about attitude (Bolton \& Drew, 1991, p. 2; Richard L Oliver, 1981, p. 31).

In the context of technology, Liao et al. (2009) find that the link between satisfaction and attitude are relevant constructs in the different stages of use. In this sense, the following hypothesis is formulated:

H3: Satisfaction has a positive impact on attitude to continuance.

Perceived usefulness is an individual's belief that using technology will improve performance. Ease of use refers to the degree to which the use of technology is effortless (Davis et al., 1989).

TTC also proposes a link between both beliefs and attitudes. Conceptually, attitudes are developed based on beliefs about the outcome of behavioral execution. To the extent that these results are valued positive or negative, the individual will positively or negatively influences his or her attitude towards such behavior (Ajzen, 1991, p. 191).

The usefulness and the ease of use are beliefs about the technology in question, and they represent external factors that motivate the attitude toward continuity (Davis et al., 1989; Liao et al., 2009). It is expected that a useful technology will result in an increase in performance and an easy technology will result in a less mental effort, if this is the case, the attitude will increase (Davis et al., 1989).

Several studies show the relationship between these beliefs and attitude empirically. For example, Bhattacherjee and Premkumar (2004), ), when evaluating the impact of beliefs (post-use) on changing attitudes after the use of technology, find that perceived usefulness impacts attitudes at different stages of use.

Based on the above, it is proposed:

H4: Perceived usefulness positively affects attitude to continuance.

H5: Ease of use positively affects attitude to continuance.

The ECM states that two constructs determine user satisfaction: the expectation about technology and the confirmation of expectations after actual use (Bhattacherjee, 2001). Expectations are the baseline against which confirmation is evaluated by users to determine an evaluative response or satisfaction (Richard L. Oliver, 1980). In this sense, confirmation is understood as the perception of the users about the congruence between the expectation of using technology and its actual performance (Bhattacherjee, 2001). 
Thus, a conceptual link between the confirmation and satisfaction is suggested. Theoretically, after using technology, the individual assesses the congruence between his/her expectations and the performance of the technology. To the extent that the expectations are confirmed, the individual will feel more satisfaction. In the opposite case, the disconfirmation of expectations will be taken as a failure, and therefore, it will generate dissatisfaction in the individual (Bhattacherjee, 2001).

Based on the above, it is expected that:

H6: Confirmation influences satisfaction positively.

The ECM considers that confirmation and usefulness are related. Conceptually, Bhattacherjee (2001) explains that users may have low levels of perceived usefulness over a new technology because they are not sure what to expect from their use. However, they may still want to accept that technology with the intention of making their user experience a basis for the formation of more accurate perceptions. Although at the beginning a low perception of usefulness can be easily confirmed, when the individual realizes that their perception was too small, he/she can raise such perception for the future.

Therefore, the following hypothesis is proposed:

H7: Confirmation positively impacts on perceived usefulness.

TTC also proposes a link between ease of use and usefulness. Davis et al. (1989) mention that a technology that is easy to use will save time and effort of the individual. This savings can be reassigned, allowing the individual to carry out more activities with the same effort or to carry out other activities. This results in a perception of usefulness.

Then, the following hypothesis is proposed:

H8: Ease of use positively affects perceived usefulness.

\section{Continuity of use in the presence of alternative technologies}

As noted above, the TPM explores the role of alternative technologies in the decision-making process of individuals to continue using technology. For this, Muthitcharoen et al. (2011) model preference as an attitude. Based on the literature of social psychology, they propose that new and current alternatives are compared in detail (attributes based on preference, ATRP) before developing a general preference (attitude based on preference, ATTP) (Einhorn, 1971; Tversky, 1969). Thus, the ATRP forms the preference by comparing specific attributes among the alternatives, especially when no prior information about them is available. On the other hand, the ATTP involves the general evaluation of the options, so that the formation of preference is based on the generic affections of individuals. This attitude is used when there is previous information about the alternatives, and there is a preference for the option that provides the most favorable affection (Muthitcharoen et al., 2011).

The TPM proposes a link between ATTP and intention. The ATTP implies that the attitudes towards the alternatives are formed in a comparative frame of reference, and allows capturing the explicit comparison between the attitudes of the users toward the use of alternative technologies. The link between ATTP and intention is based on the assumption that individuals generally minimize cognitive effort while making a decision. If users believe that an alternative technology is superior to what is currently used, this will affect the intention of continuity of use of the latter (Muthitcharoen et al., 2011, p. 212).

H9: Attitude-based preference positively influences intention to continuance.

The TPM proposes a link between the ATTP and the attitude towards the continued use of technology. This link is based on the literature of information processing, which states that users develop general preferences based on the comparison of alternatives, first at the attribute level, and then at the level of a general evaluation (Einhorn, 1971; Tversky, 1969). At this final level, it will involve positive or negative valuations, in this case, towards the use of the technologies and it will be determined the preference for some of them. Thus, if the new alternative is superior to the 
one that is currently used, users will develop a positive attitude towards the new one (Muthitcharoen et al., 2011, p. 211).

H10: Attitude-based preference positively influences attitude to continuance.

On the other hand, it is considered that the satisfaction with the use of technology affects the formation of the ATTP. Hellier et al. (2003) use the concept of brand preference (in our case, ATTP) to refer to the degree to which consumers favor a current brand compared to other brands. Theoretically, a high level of satisfaction of a brand probably provokes the individual to retain the brand and increase its preference for (Hellier et al., 2003, p. 1770).

Based on the above, the following hypothesis is considered:

H11: Satisfaction positively affects attitude-based preference.

A central proposal of the TPM is that the preference is formed from the comparison of specific attributes. Dabholkar (1994) suggests that individuals compare their beliefs related to each of the characteristics of the alternatives they have available. The author adds that this comparison then impinges on the relative attitude towards each option. Empirically, Muthitcharoen et al. (2011) find that product attributes, cost and relative risk affect the preference between a physical channel and a virtual one. Jaafar et al. (2014) show that enjoyment and relative social presence are relevant attributes that influence preference in social technologies.

Based on the above, the following hypothesis is considered:

H12: Attribute-based preference positively influences attitude-based preference.

\section{RESEARCH METHOD}

Given that the present study is ongoing research, this section describes the procedures that will be performed for data collection and analysis.

\section{Measures}

TTC-related constructs such as continuity intent, attitude toward usefulness continuity, ease of use, confirmation, and satisfaction will be measured with elements based on the work of Liao et al. (2009) and Bhattacherjee and Lin (2015). On the other hand, preference-related variables such as attitude based on preference, product preference and cost of change will be measured using the scales proposed by Muthitcharoen et al. (2011), Hellier et al. (2003) and Ebrahim, Ghoneim, Irani, and Fan (2016).

\section{Data Collection (Future Step)}

We will use survey methodology to gather individuals' responses to the items measuring both independent and dependent variables. The sample will be chosen from current USA users. Data will be collected through Amazon Mechanical Turk, which is a web-based platform where employers (called requesters) post outsourced tasks for an anonymous network of laborers (called workers) who receive compensation for their contribution (Steelman, Hammer, \& Limayem, 2014). This web site has been shown to be effective in data collection and prior studies have reported that samples collected through this platform produced similar results that those based on USA students and USA consumer panels (Steelman et al., 2014). We plan to conduct first a pilot test for checking the reliability and validity of our measurement items. For the full-sample survey, we will divide the survey in three sections: (1) items measuring control variables, (2) items measuring our independent and dependent variables, and (3) demographics. We will also include the following recommendations to detect careless responses (Huang, Curran, Keeney, Poposki, \& DeShon, 2012): (1) attention checks that have only one correct response embedded in the question, and (2) a warning statement that acknowledge participants that statistical control methods will be used to detect careless responses. To determine the minimum sample size, we follow Chin (1998)'s rule-of-thumb which establishes that a sample size should be at least 10 times (1) the largest number of formative indicators or (2) the largest number of independent variables impacting a dependent variable, whichever is greater. In our research model there are not formative indicators as discussed in the previous subsection, whereas the largest number of independent variables 
affecting a dependent variable (intention) is five. We expect to collect 500 usable responses, which is more than adequate for the PLS estimation procedures (minimum sample size is 50 participants).

\section{Data Analysis (Future Step)}

For data analysis, we will use partial least squares (PLS) technique because our study is in an early stage of theory development (Komiak \& Benbasat, 2006). SmartPLS will be used as analysis tool (Ringle, Wende, \& Becker, 2015).

As for the measurement model, reliability and convergent validity will be assessed through three tests: (1) reliability of items (items' loadings should be equal or higher than 0.7), (2) internal consistency (cronbach's alpha and composite reliability values should be equal or higher than 0.7 ), and (3) average variance extracted (AVE) (this value should be equal or higher than 0.5 ). On the other hand, discriminant validity will be checked by assessing that the square root of the AVEs is higher than the correlations among the constructs.

In addition, we will check the absence of multicollinearity among variables and common method bias. The former will be performed by examining that variance inflation factor (VIF) values are less than five when performing regression analysis (Hair, Ringle, \& Sarstedt, 2011). As for the latter, we will check that no single factor accounts for the majority of the variance by performing the Harman's single-factor test.

To assess the explanatory power of our structural model, we will analyze the amount of variance explained in the endogenous constructs (R2) and paths between variables. We will also compare three models using (Cohen, 1988)'s method (f2). Model 1 represents the full model including control variables, Model 2 represents the effect of our theoretical constructs (excluding control variables), and Model 3 represents only the effect of the control variables, which will serve as the basis to analyze the impact of the theoretical constructs. Results supporting the relevance of our independent variables should be as follow: (1) Model 1 explains a greater variance than the one explained by Model 3, and (2) the difference in explained variance between Model 1 and Model 2 is lower than the difference between Model 1 and Model 3.

\section{IMPLICATIONS (EXPECTED)}

Our research attempts to explain the continued use of a technology based on its implicit and explicit comparison with other alternatives. Thus, we will hope that this approach would theoretically contribute by extending the model of continuity to one that considers the role of individual preference for options as an explicit means of comparison.

It is also expected that, at the practical level, management considers the role of preference when designing their products. In this sense, the emphasis that is given to attributes of a product that potentially can create a differential, or provide added value, compared to other alternatives, is essential. This added value will affect the user's preference for one or the other choice, affecting its continued use over time.

\section{REFERENCES}

Ajzen, I. (1991). The theory of planned behavior. Organizational Behavior and Human Decision Processes, 50(2), $179-211$.

Bhattacherjee, A. (2001). Understanding information systems continuance: An expectation-confirmation model. MIS Quarterly, 25(3), 351-370.

Bhattacherjee, A., \& Lin, C.-P. (2014). A unified model of IT continuance: Three complementary perspectives and crossover effects. European Journal of Information Systems, 24(4), 1-10.

Bhattacherjee, A., \& Lin, C.-P. (2015). A unified model of IT continuance: Three complementary perspectives and crossover effects. European Journal of Information Systems, 24(4), 364-373. 
Bhattacherjee, A., \& Premkumar, G. (2004). Understanding changes in belief and attitude toward information technology usage: a theoretical model and longitudinal test. Mis Quarterly, 28(2), 229-254.

Bolton, R. N., \& Drew, J. H. (1991). A longitudinal analysis of the impact of service changes on customer attitudes. The Journal of Marketing, 1-9.

Cohen, J. (1988). Statistical power analysis for the behavioral sciences. Hillsdale, NJ: Lawrence Earlbaum Associates.

Chin, W. W. (1998). The partial least squares approach for structural equation modeling. In G. A. Marcoulides (Ed.), Modern methods for business research (pp. 295-336). Mahwah, NJ: Lawrence Erlbaum Associates.

Dabholkar, P. A. (1994). Incorporating choice into an attitudinal framework: Analyzing models of mental comparison processes. Journal of consumer research, 21(1), 100-118.

Davis, F. D., Bagozzi, R. P., \& Warshaw, P. R. (1989). User acceptance of computer technology: A comparison of two theoretical models. [v]. Management Science, 35(8), 982-1003.

Devaraj, S., Fan, M., \& Kohli, R. (2002). Antecedents of B2C channel satisfaction and preference: validating ecommerce metrics. Information Systems Research, 13(3), 316-333.

Drew, C., Hale, K., Hahn, W., Atwal, R., Graham, C., O'Connell, A., \& Sumner, B. (2014). Forecast Alert: IT Spending, Worldwide, 1Q14 Update.

Ebrahim, R., Ghoneim, A., Irani, Z., \& Fan, Y. (2016). A brand preference and repurchase intention model: The role of consumer experience. Journal of Marketing Management, 32(13-14), 1230-1259.

Einhorn, H. J. (1971). Use of nonlinear, noncompensatory models as a function of task and amount of information. Organizational Behavior and Human Performance, 6(1), 1-27.

Fishbein, M., \& Ajzen, I. (2011). Predicting and changing behavior: The reasoned action approach: Taylor \& Francis.

Hair, J. F., Ringle, C. M., \& Sarstedt, M. (2011). PLS-SEM: Indeed a silver bullet. The Journal of Marketing Theory and Practice, 19(2), 139-152.

Hellier, P. K., Geursen, G. M., Carr, R. A., \& Rickard, J. A. (2003). Customer repurchase intention: A general structural equation model. European journal of marketing, 37(11/12), 1762-1800.

Hong, S.-J., Thong, J. Y. L., \& Tam, K. Y. (2006). Understanding continued information technology usage behavior: A comparison of three models in the context of mobile internet. Decision Support Systems, 42(3), 1819-1834.

Hossain, M. A., \& Quaddus, M. (2012). Expectation-confirmation theory in information system research: A review and analysis. In Y. K. Dwivedi, M. R. Wade \& S. L. Schneberger (Eds.), Information systems theory: Explaining and predicting our digital society, Vol 1. (pp. 441-469). New York: Springer.

Huang, J. L., Curran, P. G., Keeney, J., Poposki, E. M., \& DeShon, R. P. (2012). Detecting and deterring insufficient effort responding to surveys. Journal of Business and Psychology, 27(1), 99-114.

Jaafar, N. I., Darmawan, B., \& Mohamed Ariffin, M. Y. (2014). Face-to-face or not-to-face: A technology preference for communication. CyberPsychology, Behavior, and Social Networking, 17(11), 702-708.

Jasperson, J. S., Carter, P. E., \& Zmud, R. W. (2005). A comprehensive conceptualization of post-adoptive behaviors associated with information technology enabled work systems. MIS Quarterly, 29(3), 525-557. 
Kivetz, R., Netzer, O., \& Schrift, R. Y. (2008). The synthesis of preference: Bridging behavioral decision research and marketing science. Retrieved from:

https://www0.gsb.columbia.edu/mygsb/faculty/research/pubfiles/3075/001_The_Synthesis_of_Preference Bridging_Behavioral_Decision_Research_and_Marketing_Science.pdf

Komiak, S. Y., \& Benbasat, I. (2006). The effects of personalization and familiarity on trust and adoption of recommendation agents. MIS Quarterly, 941-960.

Liao, C., Palvia, P., \& Chen, J.-L. (2009). Information technology adoption behavior life cycle: Toward a Technology Continuance Theory (TCT). International Journal of Information Management, 29(4), 309320.

Lin, J., Chan, H. C., \& Wei, K. K. (2006). Understanding competing application usage with the theory of planned behavior. Journal of the American Society for Information Science and Technology, 57(10), 1338-1349.

Lin, J., Chan, H. C., \& Wei, K. K. (2011). Understanding competing web application platforms: An extended theory of planned behavior and its relative model. IEEE Transactions on Engineering Management, 58(1), 21-35.

Muthitcharoen, A. M., Palvia, P. C., \& Grover, V. (2011). Building a model of technology preference: The case of channel choices. Decision Sciences, 42(1), 205-237.

Oliver, R. L. (1980). A cognitive model of the antecedents and consequences of satisfaction decisions. [Article]. Journal of Marketing Research (JMR), 17(4), 460-469.

Oliver, R. L. (1981). Measurement and evaluation of satisfaction processes in retail settings. Journal of retailing, $57(3), 25-48$.

Ringle, C. M., Wende, S., \& Becker, J.-M. (2015). SmartPLS 3. Boenningstedt: SmartPLS GmbH, http://www. smartpls. com.

Samson, A. (2015). The behavioral economics guide 2015 (with an introduction by Dan Ariely): BehavioralEconomics. com.

Shaikh, A. A., \& Karjaluoto, H. (2015). Making the most of information technology \& systems usage: A literature review, framework and future research agenda. Computers in Human Behavior, 49, 541-566.

Steelman, Z. R., Hammer, B. I., \& Limayem, M. (2014). Data Collection in the Digital Age: Innovative Alternatives to Student Samples. MIS quarterly, 38(2), 355-378.

Thong, J. Y. L., Hong, S.-J., \& Tam, K. Y. (2006). The effects of post-adoption beliefs on the expectationconfirmation model for information technology continuance. International Journal of Human-Computer Studies, 64(9), 799-810.

Tversky, A. (1969). 19Intransitivity of Preferences. Preference, Belief, and Similarity, 433.

Venkatesh, V., Brown, S. A., Maruping, L. M., \& Bala, H. (2008). Predicting different conceptualizations of system use: the competing roles of behavioral intention, facilitating conditions, and behavioral expectation. MIS quarterly, 483-502.

Venkatesh, V., Thong, J., \& Xu, X. (2012). Consumer acceptance and use of information technology: extending the unified theory of acceptance and use of technology. MIS Quarterly, 36(1), 157-178. 